\title{
A ADAPTAÇÃO CINEMATOGRÁFICA DE UMA TRAGÉDIA AMERICANA E OTELO EM MATCH POINT
}

\author{
Ana Paula Bianconcini Anjos* \\ Universidade de São Paulo \\ São Paulo, SP, Brasil
}

\section{Resumo:}

O artigo retoma o histórico das adaptações cinematográficas do romance Uma Tragédia Americana (1925), de Theodore Dreiser, recuperando as discussões sobre a cena do afogamento. Os estudos de Sergei Eisenstein sobre o uso do monólogo interior no cinema e o comentário de Bertolt Brecht a respeito da trilha sonora na adaptação do romance de Dreiser oferecem importante ponto de entrada para a análise do filme Match Point (2005), de Woody Allen. Em Match Point, o uso da trilha sonora, notadamente a colagem com a ópera Otelo (1887), de Giuseppe Verdi, permite que o espectador reflita sobre as possibilidades narrativas da adaptação para o cinema. Palavras-chave: Woody Allen; Theodore Dreiser; Sergei Eisenstein; Ópera; Cinema e Guerra

\section{THE FILM ADAPTATION OF AN AMERICAN TRAGEDY AND OTHELLO IN MATCH POINT}

\begin{abstract}
The aim of the present article is to recover the history of the cinematic adaptations of the novel An American Tragedy (1925), by Theodore Dreiser, reinstating the discussions of the drowning scene. Sergei Eisenstein's writings on the possibilities of the use of the interior monologue in films and Bertolt Brecht's remarks on the role of the soundtrack in Dreiser's novel adaptation offer an important entry into the analysis of the film Match Point (2005), by Woody Allen. In Match Point, the use of the soundtrack, in particular the collage with the opera Otello (1887), by Giuseppe Verdi, instigates the spectator to reflect on the narrative possibilities of film adaptation.
\end{abstract}

Keywords: Woody Allen; Theodore Dreiser; Sergei Eisenstein; Opera; Cinema and War

\section{Uma Tragédia Americana}

Nos oitenta anos de Uma Tragédia Americana (1925), de Theodore Dreiser, Woody Allen lançou Match Point (2005), história de um arrivista social que mata sua amante, grávida dele, para manter o casamento e a rede de privilégios da família de sua esposa rica. A semelhança entre o enredo de Dreiser e o de Woody Allen passou despercebida pela crítica, que, em grande parte, restringiu-se a identificar a citação explícita ao filme de George Stevens Um Lugar ao Sol (1951), a mais conhecida adaptação cinematográfica de Uma Tragédia Americana.
O romance de Dreiser baseou-se na sentença midiática de Chester Gillette, jovem norte-americano que foi condenado e executado no começo do século XX no estado de Nova York pelo assassinato de sua namorada, Grace Brown. O jovem pleiteava por sua inocência, mas o júri condenou-o rapidamente à cadeira elétrica. O caso obteve extensa cobertura de mídia, a imprensa explorou as cartas na qual a moça grávida suplicava por resposta; a fuga do jovem, após o afogamento de Grace Brown; e a raquete de tênis enterrada. Os jornais da região financiaram a ida da mãe de Chester Gillette ao local para registrar o fato jornalístico, a sentença do fi-

Professora da área de Inglês do Departamento de Letras Modernas na Universidade de São Paulo. Possui doutorado e mestrado em Estudos Linguísticos e Literários em Inglês pelo mesmo departamento. Sua grande área de trabalho concentra-se em Literatura e Cinema. Endereço de email: anjos.anapaula@gmail.com 
lho. Em 2005, quase um século após o ocorrido, Woody Allen retoma trama similar, mas com mudanças significativas, para retratar a ascensão de um jovem arrivista irlandês na capital financeira da Europa.

De acordo com Lawrence Hussman, "nenhum romancista norte-americano despertou tanto interesse em diversos cineastas lendários como Dreiser" (1995, p. 176). Entre eles, destacam-se os estudos inconclusos de D. W. Griffith, Ernst Lubitsch e Sergei Eisenstein. Dos filmes que foram realizados a partir do romance de Dreiser podem ser considerados como adaptações: Aurora (1927), de F.W. Murnau, Uma Tragédia Americana (1931), de Joseph von Sternberg, e Um Lugar ao Sol (1951), de Stevens. Ao analisar as adaptações de Eisenstein, Sternberg e Stevens, Mandy Merck afirma que essas tragédias americanas são produções de Hollywood. De acordo com a autora, a relevância contemporânea do romance de Dreiser está em retratar uma sociedade ainda fascinada pela ambição e seu preço, obcecada pela cobertura midiática de julgamentos. Segundo Merck, o próprio Dreiser considerava os Estados Unidos como real autor da tragédia de Clyde: "escrito na Era do Jazz, filmado pela primeira vez na Grande Depressão e depois, no auge do Macarthismo, o romance e as suas adaptações constituem e foram constituídos pelas reviravoltas do Estado, seu antagonista e tema" (MERCK, 2007, p. 5).

O filme Aurora de Murnau baseou-se na coleção de contos Viagem a Tilsit, do escritor alemão Hermann Sudermann, mas o roteiro guarda semelhanças significativas com o romance de Dreiser, lançado apenas dois anos antes. Em Aurora, um pequeno fazendeiro planeja $o$ assassinato de sua esposa, movido pelo encantamento da cidade e de uma jovem arrivista. Contudo, no momento decisivo, ele não comete o crime; observam-se os seus olhos agitados, as sobrancelhas arqueadas, suas mãos trêmulas. Durante o passeio de barco, a esposa descobre o intento do marido e afasta-se dele. Em meio ao caos da metrópole, o casal reaproxima-se. No retorno à fazenda, uma forte tempestade faz o barco virar. A esposa é salva pelos gravetos que o marido lhe dera e por outros pequenos proprietários que a encontram. Diferentemente do romance de Dreiser, no desfecho do filme de Murnau, o casal restabelece-se e volta à pequena propriedade junto ao filho; por sua vez, a jovem forasteira é expulsa da comunidade. Aurora foi um dos primeiros filmes a sincronizar som e imagem. No lançamento do filme de Murnau, realizado em 1927 na Times Square em Nova York, a Fox News promoveu também um jornal cinematográfico, apresentado antes do filme, no qual o general fascista italiano Benito Mussolini conclamava, em inglês, aos imigrantes residentes nos EUA para trabalhar e ajudar a "fazer a América grande". Assim como o romance de Dreiser, o filme de Murnau desfaz ilusões.

É sabido que o nome do protagonista de Dreiser, Clyde Griffiths, teria sido inspirado pelo patriarca de Hollywood, D. W. Griffith. Dreiser escreveu os primeiros rascunhos de Uma Tragédia Americana no início dos anos 1920, em Hollywood, enquanto acompanhava sua namorada, Helen Richardson, aspirante a atriz de cinema. Neste período, Dreiser também procurou escrever roteiros, como uma forma de fugir de sua precária condição financeira, mas frustrou-se com Hollywood e o constante assédio dos executivos dos estúdios por jovens atrizes em busca de emprego. De acordo com Merck, Dreiser constrói o romance "como se Hollywood fosse cúmplice desta tragédia" (MERCK, 2007, p. 6-7). Em Uma Tragédia Americana, a repercussão do caso Clyde Griffiths é descrita como um grande evento midiático e cinematográfico: “Amendoins!' 'Pipoca!' 'Cachorro-quente!' 'Leia a história de Clyde Griffiths, com todas as cartas de Roberta Alden. Por apenas 25 centavos!"' (DREISER, 2000, p. 662). Em certo momento, o narrador comenta que o caso Clyde configurava-se como uma oportunidade única para fazer propaganda do promotor de justiça Mason, tendo em vista que naquele julgamento, exaustivamente repercutido pela mídia, os olhos de todos os cidadãos norte-americanos estariam sobre ele: "Era como se alguém tivesse exclamado de repente: 'Luzes! Câmera!" (DREISER, 2000, p. 671).

$\mathrm{Na}$ tradição macabra norte-americana de espetacularização de tragédias, Merck lembra que no ano em que se comemorou o centenário do caso Chester Gillette e Grace Brown houve o lançamento da ópera Uma Tragédia Americana, de Tobias Picker, no Metropolitan Opera em Nova York. Apesar das semelhanças entre o 
enredo de Dreiser e o de Woody Allen, Merck considera que o cineasta sacrificou a ironia do romancista: "a indignação de Dreiser com a injustiça norte-americana, mascarada por seu ethos igualitário, não foi transferida para o Reino Unido" (MERCK, 2007, p. 6-7).

No entanto, conforme argumentarei a seguir, em Match Point, no destino de Chris Wilton e Nola Rice está cifrada a representação de uma tragédia contemporânea, fruto da aliança belicista entre EUA e Reino Unido. Assim como Dreiser, Woody Allen caracteriza a indústria do entretenimento como cúmplice do crime.

É significativo que o cineasta tenha adaptado $\mathrm{Ma}$ tch Point para Londres e afirmado que as mudanças do cenário nova-iorquino para o londrino foram apenas "cosméticas" (MATLOFF, 2010). O cineasta não obteve financiamento para filmar em Wall Street, por discordar das alterações no roteiro que foram sugeridas pelos executivos responsáveis pelo financiamento do filme. Com os recursos da BBC e as condições de produção garantidas, o cineasta nova-iorquino adapta esta tragédia americana para o Reino Unido, realizando modificações na passagem de Wall Street para a City, centro financeiro londrino.

A questão do financiamento das artes e da censura na indústria cinematográfica acompanha a história das adaptações de Uma Tragédia Americana. Em sua breve passagem por Hollywood nos anos 1930, Sergei Eisenstein trabalhou no roteiro de Uma Tragédia Americana e, como resultado desta obra inconclusa, o cineasta russo escreveu uma das mais contundentes reflexões sobre o cinema moderno, reunidas no artigo "Sirva-se!" (1932). No famoso ensaio de Eisenstein, ainda não traduzido diretamente do russo para o português, o diretor explica a disputa em relação ao tratamento do enredo. O conflito entre, de um lado, Eisenstein e Dreiser, e, do outro, os executivos de Hollywood, travou-se pelo direito de decidir sobre o fio condutor da narrativa. $\mathrm{Na}$ discussão interpretativa e política sobre a adaptação cinematográfica do romance, a questão central levantada pelos executivos da Paramount era: afinal Clyde Griffiths, o protagonista de Dreiser, seria culpado ou não pelo assassinato de sua namorada, Roberta Alden?

A adaptação cinematográfica de Uma Tragédia Americana que retratasse Clyde como inocente se- ria considerada "antiamericana", por representar "um monstruoso desafio à sociedade norte-americana" (EISENSTEIN, 2002, p. 98) - essa foi a justificativa, apresentada por B. P. Schulberg, diretor de produção dos estúdios Paramount, detentor dos direitos de adaptação do romance, para interromper o financiamento do filme de Eisenstein.

De acordo com o cineasta russo, apesar da indiscutível evidência de que Clyde planejara o assassinato, no momento do crime, ele vacila. No entanto, percebendo as intenções de Clyde, Roberta desespera-se. Ela aproxima-se do rapaz e desequilibra-se, bate o rosto na câmera fotográfica de Clyde; a canoa vira. Para mostrar o febril fluxo de pensamentos do protagonista, Dreiser descreve os murmúrios interiores de Clyde em um monólogo interior indireto:

Você pode salvá-la. Mas ao mesmo tempo não pode! Veja como ela se debate. Ela está atordoada. Ela é incapaz de salvar-se, está aterrorizada, se você se aproximar dela agora, isso pode provocar a sua morte também. Mas você deseja viver! E a vida dela vai fazer a sua não valer a pena a partir de agora. Espere um pouco - uma fração de minuto! Espere - espere - ignore a piedade deste apelo. E então - então - lá está! Olhe. Acabou. Ela está afundando agora. Você nunca mais vai vê-la viva - para sempre. (DREISER, 1925, p. 514)

Nas reflexões de Eisenstein sobre o roteiro de Uma Tragédia Americana encontram-se suas considerações acerca das possibilidades de uso do monólogo interior, no qual "a câmera tinha de ir 'dentro' de Clyde: auditiva e visualmente, era preciso mostrar a febril corrida de pensamentos intercalados com a realidade externa" (EISENSTEIN, 2002, p. 103).

De acordo com Ismail Xavier, na justaposição de imagens e palavras, Eisenstein buscava "fazer avançar, no cinema, técnicas modernas, como a do monólogo interior e a das montagens descontínuas, de modo a fazê-lo um medium mais rico do que a própria literatura" (1997, p. 128). Xavier propõe entender o diálogo entre literatura e cinema, a partir das reflexões de Eisenstein, sobretudo a questão do verticalismo, na qual "é preciso ter um efeito de simultaneidade que preserve, 
ao mesmo tempo, a disjunção entre som e imagem, seu entrechoque, estranhamento" (1997, p. 128).

A questão da disjunção entre som e imagem na adaptação do romance de Dreiser também foi trabalhada por Bertolt Brecht. Tanto nos estudos de Brecht como nos escritos de Eisenstein sobre a adaptação de Uma Tragédia Americana para o cinema, a cena do afogamento adquiriu centralidade, pois conforme o modo de tratamento, o uso da música e do monólogo interior, Clyde seria considerado culpado ou inocente.

Ao argumentar sobre a separação dos elementos no filme narrativo, Brecht explica que o entrechoque entre música e ação pode proporcionar novos efeitos no cinema. Para isso, o compositor deveria fazer parte do processo criativo do filme, e a música teria uma função de economia das cenas, evitando a redundância. Nesse ponto, Brecht cita a adaptação de Uma Tragédia Americana:

Um jovem leva a namorada para um passeio de canoa no lago, o barco vira e ele deixa a garota se afogar. O compositor tem duas opções: ele pode antecipar os sentimentos do público por meio da música de acompanhamento, desenvolvendo a tensão, aumentando o mal do acontecimento, etc. Ou então, ele pode expressar por meio da música a serenidade do lago, a indiferença da natureza, o caráter cotidiano do evento, na medida em que é um simples passeio de barco. Se ele escolher esta última opção, permitirá que o assassinato pareça ainda mais terrível e antinatural, ele dá à música uma função mais independente. (BRECHT, 2000, p. 14)

O breve e preciso comentário de Brecht contém atenção semelhante à de Dreiser e Eisenstein; a saber, a representação da cena do afogamento em Uma Tragédia Americana deveria salientar o caráter cotidiano do crime. Dreiser e Eisenstein trabalharam juntos para que o filme dirigido pelo cineasta russo fosse realizado. Dreiser inclusive elogiou as alterações feitas por Eisenstein ao desconstruir a figura monumental da mãe de Clyde que, no momento decisivo, entregue ao dogma cristão, também desacredita o filho.

Entretanto, os estúdios Paramount, que detinham os direitos autorais para a adaptação cinematográfica do romance de Dreiser, não concordaram com o tra- tamento dado por Eisenstein; eles queriam um "filme policial simples sobre um assassinato e o amor de um rapaz por uma moça" (EISENSTEIN, 2002, p. 98) e entregaram o direito de adaptação do romance a Josef von Sternberg. A adaptação do cineasta austríaco foi feita à revelia de Dreiser, que levou os estúdios Paramount aos tribunais para que sua obra fosse adaptada por Eisenstein. Uma Tragédia Americana (1931) de Josef von Sternberg, todavia, é mais do que um simples caso policial, mas não privilegia, como queriam Eisenstein e Dreiser, a questão do crime como "a soma total das relações sociais, cuja influência Clyde sofreu em todos os estágios de desenvolvimento de sua biografia e caráter, no decorrer do filme" (EISENSTEIN, 2002, p. 98).

$\mathrm{Na}$ abordagem de Eisenstein, a inocência de Clyde representava um "monstruoso desafio" a uma sociedade cujo "mecanismo leva um jovem sem caráter a uma tal situação, e então, invocando moralidade e justiça, senta-o na cadeira elétrica" (1932, p. 100). Sentenciado à pena de morte pelo sistema judicial norte-americano, "Clyde também se torna um joguete nas mãos da nada cega engrenagem da justiça burguesa, engrenagem usada como um instrumento de intriga política" (2002, p. 102). Assim, o destino particular do caso Clyde tornase uma "tragédia americana em geral - uma história característica de um jovem norte-americano do início do século XX" (EISENSTEIN, 2002, p. 102).

Muito antes da Era da Lista Negra - de 1947-1960, período nefasto da história norte-americana, de repressão política organizada e executada pelo Estado com anuência de parte da população -, o projeto de Dreiser e Eisenstein não pôde ser realizado, por conta da censura dentro dos estúdios cinematográficos. Lançado no auge da Era da Lista Negra, o filme de George Stevens deve ser entendido dentro desse contexto. Durante o período, Stevens ocupou cargos-chave em Hollywood: foi presidente da Associação de Diretores dos EUA (1941-43 e 1946-48) e da Academia de Cinema, Artes e Ciências (1958-59) - entre outras atribuições, entidade responsável pela entrega dos prêmios Oscar. Ademais, durante a Segunda Guerra Mundial, Stevens trabalhou na Unidade de Cobertura Especial do Exército Americano, responsável pela documentação cinematográfica da investida norte-americana no conflito. Conforme 
procurarei demonstrar, o desempenho de Stevens em cargos administrativos centrais da indústria cinematográfica norte-americana elucida Um Lugar ao Sol.

No filme de 1951, o protagonista de Dreiser, Clyde Griffiths, chama-se George Eastman, sobrinho de um importante empresário da indústria de vestuário. Além da escolha do nome do protagonista promover identificação com o próprio cineasta, George Eastman é o nome do inventor do filme fotográfico e fundador da empresa Kodak. Em 1942, após assistir aos filmes de propaganda nazista de Leni Riefenstahl, Stevens alistou-se no Exército americano. Ele foi convocado pelo general Dwight Eisenhower a dirigir a cobertura cinematográfica do combate, mas "enquanto documentava o avanço das forças aliadas em Berlim, Stevens trazia consigo uma câmera $16 \mathrm{~mm}$ e caixas de filme Kodakchrome" que permitiram que ele filmasse um diário pessoal da guerra, em cores, rara filmagem colorida dos campos de concentração em Auschwitz e Ravensbrück.

Afora a participação de Stevens na Segunda Guerra Mundial, é preciso considerar a sua atuação na Era da Lista Negra. Em 1950, como membro da Associação de Diretores dos EUA, Stevens intercedeu para que o anticomunista Cecil DeMille, um dos fundadores de Hollywood e da Paramount Pictures, não conseguisse o impeachment do então presidente da entidade Joseph Mankiewicz. Corroborando a perseguição política do período, DeMille queria tornar obrigatório o juramento de lealdade, no qual os membros da Associação de Diretores teriam que assinar um termo em que negavam qualquer envolvimento com ideias comunistas. Após inúmeras disputas, o juramento de lealdade anticomunista foi implementado pela Associação e durou de 1950 até 1966 (ULMER, 2011). Como presidente da Academia de Cinema, Artes e Ciências, Stevens questionou o escritor blacklisted Dalton Trumbo sobre a autoria do roteiro de Arenas Sangrentas, filme que havia ganhado o Oscar de melhor roteiro original em 1957, assinado pelo testa-de-ferro de Trumbo, Robert Rich. Trumbo respondeu com uma carta endereçada a George Seaton, que havia ocupado o cargo de presidente da Academia anteriormente, na qual afirmava que o seu único intuito era utilizar a publicidade gerada pela estatueta para "acabar com a lista negra" (TRUMBO, 1959, p. 464).
Além do aparato de censura em Hollywood estar em pleno apogeu, em meio às acusações e delações do período que acabaram com a carreira de muitos dos mais talentosos cineastas, Um Lugar ao Sol ganhou seis estatuetas do Oscar em 1952, incluindo a de melhor diretor. Uma das passagens mais emblemáticas do filme de Stevens é o sorriso de Elizabeth Taylor, como bem observou Jean-Luc Godard em Histoire(s) du cinéma (1989). No primeiro capítulo deste conjunto de vídeos realizado ao longo de dez anos (entre 1988 e 1998), Godard contrapõe a felicidade de Taylor ao horror do Holocausto. Em uma cena de Histoire(s) du cinéma, exemplo de montagem dialética, Godard comenta, em voz off, o envolvimento de Stevens na Segunda Guerra Mundial, contrapondo a cena do lago de Um Lugar ao Sol aos corpos putrefatos em Auschwitz:

E se George Stevens não tivesse utilizado o primeiro filme de $16 \mathrm{~mm}$ em cores em Auschwitz e Ravensbrück nunca, sem dúvida [imagens dos corpos enfileirados]; a felicidade de Elizabeth Taylor não teria encontrado um lugar ao sol. $\mathrm{Oh}$, que maravilha poder olhar aquilo que não vemos. Oh, doce milagre dos nossos olhos cegos!

No artigo "Elizabeth Taylor em Auschwitz", Alan Wright considera a sobreposição de fotografias de cadáveres empilhados e a imagem do sorriso tranquilo de Taylor, enquanto ela embala Montgomery Clift em seus braços às margens do rio, como a "inserção de um interlúdio sutil do filme de Stevens transformada em meditação elegíaca sobre o Holocausto, a relação entre o cinema e a memória, e a crise do relato em face do terror e do assassinato em massa" (WRIGHT, 2000, p. 51). Nesse ponto, Wright cita um trecho de uma entrevista de Godard concedida a Serge Daney nos anos 1980:

Em Um Lugar ao Sol há um profundo sentimento de felicidade que eu raramente encontro em outros filmes, mesmo nos muito melhores. É um sentimento simples e secular de felicidade, um momento com Elizabeth Taylor. E quando descobri que Stevens filmou os campos de concentração e que para a ocasião a Kodak lhe dera os seus primeiros rolos de filme colorido em $16 \mathrm{~mm}$, isso explicou para 
mim como ele pôde fazer aquele close-up com a Elizabeth Taylor que radiava uma espécie de felicidade obscura... (WRIGHT, 2000, p. 51-52)

De acordo com Beatriz Sarlo, Godard sublinha a ironia brutal do cinema no pós-Segunda Guerra Mundial, fábrica de sonhos difusora do sorriso das estrelas: "porque Auschwitz pôde ser filmada em cores, três ou quatro anos depois, pudemos assistir à felicidade de Elizabeth Taylor na tela de cinema" (SARLO, 2003, p. 34). Sarlo entende que a felicidade de Elizabeth Taylor demonstra "o outro poder do capitalismo como potência imaginária que repousa sobre uma certa beleza, a do corpo das mulheres" (SARLO, 2003, p. 34). Nessa fábrica de produção de estrelas, “o mais fantástico dos imaginários foi aperfeiçoado, apoiado sobre os corpos e não só sobre as representações dos corpos" (SARLO, 2003, p. 34).

Nesse ponto, proponho uma breve comparação entre Um Lugar ao Sol e Match Point, recuperando a análise de Godard sobre Stevens e a de Sarlo sobre Godard, assim como os apontamentos de Eisenstein e Brecht sobre a questão do tratamento na adaptação do romance de Dreiser.

Em Match Point, na cena da sala de jogos da casa de campo, observa-se a representação do corpo feminino como objeto fetichista do olhar masculino. Nesta apresentação da personagem interpretada por Scarlett Johansson, que parodia o clichê hollywoodiano da $f e$ mme fatale e comenta criticamente o filme de Stevens, observa-se o encontro de duas estrelas de cinema.

Enquanto em Um Lugar ao Sol a partida de bilhar unia Elizabeth Taylor, no papel da jovem rica Angela Vickers, com Montgomery Clift, que interpretou George Eastman, em Match Point, o encontro entre duas celebridades (Jonathan Rhys Meyers e Scarlett Johansson) é apresentado como uma competição violenta e desigual durante uma partida de pingue-pongue. Na sala de jogos do filme de Woody Allen, ouve-se primeiro o som da bolinha de pingue-pongue e, posteriormente, é introduzida a personagem Nola; trata-se de um som estridente e rebaixado, se comparado, conforme propõe o filme, com a de tênis, na cena de apresentação do protagonista. Por meio da utilização da técnica da câmera subjetiva, que permite que o espectador acompanhe a cena sob o ponto de vista dos personagens, o especta- dor observa a estrela de cinema como objeto do desejo masculino. Nola é caracterizada como adversária do protagonista e apresentada sob o jugo do herdeiro Tom Hewett e de seu convidado especial, o instrutor de tênis Chris Wilton. Na cena, o anfitrião controla a disposição e o movimento dos jogadores na sala.

Assim como os jovens herdeiros no filme de Woody Allen, Tom e Chloe Hewett entretêm-se com Chris e Nola, em Um Lugar ao Sol, Angela observa, sorri e controla as ações do protagonista. No filme de Stevens, George venera a vida dos ricos, por meio das colunas sociais. O interesse de Angela pelo jovem Eastman advém dos atributos físicos do protagonista, o qual se assemelha ao primo endinheirado. Desprezado por seus parentes, George é conduzido ao convívio dos ricos por Angela, que desfila em meio aos convivas com seu par exótico. Assim como Dreiser caracterizara o personagem Clyde como um forasteiro em relação à cidade e à família de seu tio rico, Stevens condensa a informação na cena na qual George e Angela são apresentados. Enquanto em Um Lugar ao Sol George é desprezado pelos convidados da festa, o protagonista de Match Point procura assemelhar-se aos ricos por meio do sotaque, das práticas esportivas, das roupas, do gosto por ópera e pelos clássicos da literatura. Em comparação ao filme de Woody Allen, a proximidade de classe entre os personagens Chris e Nola no primeiro encontro contrasta com a distância social entre George e Angela, a qual recusa o convite para jogar com o rapaz e ridiculariza-o. Nos dois filmes, a aproximação/distância entre os personagens deve-se à semelhança/diferença de classe.

Em Um Lugar ao Sol, no encontro do protagonista com o tio na sala de jogos, Earl Eastman, o anfitrião da festa, pede que o sobrinho escreva para a mãe contando sobre a promoção que ele ofereceu a George. O industrial relata à convidada suas benfeitorias sociais: "Eu o fiz subir um degrau. Ele é um garoto esperto".

No filme de Stevens, assim como no romance de Dreiser, $\mathrm{o}$ aspecto religioso permanece na caracterização da personagem da mãe do protagonista que é missionária. No de Woody Allen, o nome do protagonista faz referência a Cristo; ademais, o pai do personagem é caracterizado, pelo próprio filho, como um irlandês fanático religioso que, "após perder as duas pernas, encontrou Je- 
sus". Em Match Point, o niilismo de Chris sobre o conflito separatista irlandês reverte-se na caracterização do protagonista como um aliado inglês a serviço dos Hewett.

Se no filme de Stevens o sorriso obscuro de Elizabeth Taylor cristaliza-se na tela, no imaginário do protagonista e dos espectadores para a contemplação da estrela de cinema, no de Woody Allen, o close-up final em Scarlett Johansson revela o rosto cadavérico de Nola, antítese da felicidade de Chloe Hewett - esposa insípida, cuja maternidade fora tão programada e executada como a manutenção de seu casamento.

Enquanto Um Lugar ao Sol trata da trajetória de um arrivista social que termina na cadeira elétrica, Match Point apresenta o crime sem castigo, relacionando a tragédia no subúrbio londrino - reproduzida pelos tabloides como um acaso rotineiro nas grandes cidades - com a felicidade espúria da família Hewett. No brinde final ao herdeiro, o sorriso da família restabelecida repousa sobre os corpos dos fantasmas: Nola, a senhora Eastby e o filho de Nola e Chris, vítimas que o protagonista chama de "danos colaterais". A citação retoma discurso utilizado na Guerra do Iraque (2003-2011), na qual as perdas civis foram apresentadas aos cidadãos do mundo como "danos colaterais" em nome de um "grande esquema", a Guerra ao Terror.

\section{Otello}

Repetidamente, no primeiro capítulo das Histoire(s) du cinéma, Godard, em voz off, afirma: "A guerra está aî". Ao longo do trabalho, o filme traça relações entre a indústria cinematográfica e a das armas. Ao contrapor as imagens do horror da guerra ao deleite das celebridades, o cineasta declara: "o sofrimento não é uma estrela".

Em Match Point, na cena do assassinato, Woody Allen reencena a tragédia do Mouro de Veneza, de William Shakespeare. Na composição feita pelo cineasta, um irlandês em defesa dos interesses britânicos representaria o Mouro de Veneza contemporâneo e Desdêmona não seria a filha rica do senador veneziano, mas uma atriz faminta, senhorita Rice, do Colorado. Conforme argumentarei a seguir, o filme propõe rediscutir a tragédia de Otelo e Desdêmona à luz da desastrosa aliança entre EUA e Reino Unido na Guerra do Iraque.
Para o crítico cultural Alan Sinfield, a obra de William Shakespeare pode ser entendida como um teatro de guerra, no qual a alta cultura exerce papel fundamental na legitimação do discurso beligerante:

Para muitas pessoas, Shakespeare representa a arte e nobreza espiritual, o que pode muito bem parecer incompatível com os detalhes sobre a aquisição de armas e a matança de pessoas. Esse nunca foi um problema de princípio no período elisabetano. ... A alta cultura não parecia incompatível com o armamento. (SINFIELD, 1992, p. 6)

Partindo de um anúncio publicitário da Artilharia Real, Sinfield demonstra como a empresa britânica utiliza o teatro Shakespeare Globe para legitimar a empreitada armamentista, associando o palco elisabetano ao campo de batalhas e enaltecendo o mercado global em que atua através da "tradição e excelência britânicas" (SINFIELD, 1992, p. 3), além da cooperação militar com empresas norte-americanas. O crítico lembra que, em 1987, a então primeira-ministra britânica Margaret Thatcher privatizou a Artilharia Real, por considerar que "não era mais possível ao Estado manter uma organização e sustentá-la com um sistema de armamento moderno" (SINFIELD, 1992, p. 4). Desde a derrocada do império britânico, as oportunidades para o Reino Unido usar os seus navios e aviões restringiram-se a atuar como "um satélite dos EUA" (SINFIELD, 1992, p. 4).

A influência norte-americana sobre o Reino Unido não se faz apenas no setor das armas, mas também da cultura. $\mathrm{O}$ crítico lembra que com a transferência do poder imperial do Reino Unido para os EUA, eles imprimiram o seu jeito de fazer as coisas globalmente, incluindo os estudos acadêmicos sobre Shakespeare, os quais estão dominados por especialistas e críticos norte -americanos. Em diversos momentos do texto, Sinfield associa os personagens das tragédias de Shakespeare a políticos contemporâneos, como por exemplo, Ronald Reagan assemelhar-se-ia a Júlio César; e Margaret Thatcher representaria uma espécie de Cleópatra moderna.

Conforme Sinfield, "o sucesso de Shakespeare foi feito para simbolizar um suposto destino inglês imperial para civilizar o mundo todo" (1992, p. 6-7). O autor 
argumenta, porém, que ao invés de validar, a conexão com Shakespeare poderia destruir as ambições da empresa de armas. A contrapelo do projeto da ideologia, que apaga contradições e conflitos, o crítico materialista cultural propõe o estudo de Shakespeare "para minar a belicosidade estatal e dizer algo diferente" (SINFIELD, 1992, p. 10). A tarefa do crítico seria, portanto, a de evitar que esses '“documentos da civilização' sejam cooptados para reforçar a plausibilidade das histórias de opressão" (SINFIELD, 1992, p. 26).

A partir deste ponto, retomo a referência da tragédia de Otelo em Match Point para entendê-la como a dramatização de uma desordem específica e atroz, e a sua resolução que repõe a ordem estabelecida. Se o sentido trágico "é sempre cultural e historicamente condicionado" (WILLIAMS, 2002, p. 77), o filme de Woody Allen deve ser analisado como uma tragédia moderna, na qual a composição da trilha sonora exerce papel fundamental.

O excerto "Desdemona rea! [...] Si, pel ciel marmoreo giuro", colagem musical composta a partir do segundo ato, cena cinco, da ópera Otello, de Giuseppe Verdi, é inserido como música extra-diegética, antes, durante e após o crime, o que provoca tanto uma comparação entre a tragédia de Otelo e a de Chris, como relaciona cenas aparentemente desconexas: o acordo financeiro no prédio de negócios, o crime no apartamento do subúrbio e o encontro do casal no teatro.

Das nove óperas utilizadas na trilha sonora do filme, cinco são composições de Giuseppe Verdi ( $L a$ Traviata, Rigoletto, Macbeth e Otello). O cineasta usa cinco gravações antigas do tenor Enrico Caruso (Il Trovatore, Salvatore Rosa, I pescatori di perle, Macbeth e L'elisir d'amore), feitas no início do século XX, mas que foram restauradas. As quatro óperas em que Woody Allen utiliza gravações feitas pela Slovak Radio Symphony Orchestra são: La Traviata, Rigoletto, Guillaume Tell e Otello. Nesta última, o cineasta não utiliza os dois excertos, "Ora e per sempre addio" e "Si, pel ciel marmoreo, giuro!", da famosa gravação de Enrico Caruso de Otello feita em 1914, um pouco antes da morte do tenor, que se preparava para interpretar o Mouro de Veneza. Em Match Point, o trecho utilizado "Desdemona rea! [...] Si, pel ciel marmoreo, giuro" é de uma gravação de 1994 feita pela orquestra eslovaca, sob a regência de Johannes Wildner; o tenor Janez Lotric interpreta Otelo, e o barítono Igor Mozorov, Iago. Conforme demonstrarei, nesta gravação usada por Woody Allen existem diversas intervenções no libreto original de 1887 de Arrigo Boito e composição musical de Giuseppe Verdi, baseada na tragédia de William Shakespeare.

Além da ópera Otello, a cena do assassinato em Match Point faz referência ao romance Crime e Castigo (1866), de Fiódor Dostoiévski. Anteriormente ao homicídio, a citação ao escritor russo é utilizada pelo protagonista como capital cultural, basta lembrar o momento em que Chris troca o romance Crime e Castigo pelo manual sobre Dostoiévski, Cambridge Companion. Para convencer a matriarca de que se trata de um jovem confiável, Alec Hewett destaca a conversa que teve com o futuro genro sobre o autor russo. Entre os requisitos dos executivos das transnacionais, a prática de esportes e as atividades culturais configuram-se como atributos indispensáveis para o trabalho nas empresas. No entanto, a despeito dos personagens, Match Point relaciona a todo momento cultura e crime. A maneira precisa com que a trilha sonora é inserida no filme contradiz, por vezes, o discurso do protagonista. O tema da sorte, por exemplo, é reiterado pelo uso da ária "Uma Furtiva Lágrima", da ópera $O$ Elixir do Amor. A ópera de Gaetano Donizetti, de 1832, trata da história de um jovem camponês (Nemorino) apaixonado pela bela e rica Adina. Tímido, Nemorino não consegue conquistar a amada. Ele recorre a Dulcamara em busca de um poderoso elixir. O charlatão vende um frasco de vinho Bordeaux como se fosse elixir para Nemorino. Após entusiasmar-se sob o efeito do Bordeaux, o jovem camponês sai vitorioso. Sem saber que seu tio rico morreu e que se tornara herdeiro de uma grande fortuna, Nemorino atribui a sua "sorte" ao elixir. Após o "sucesso do elixir", Dulcamara enriquece, vendendo todo o seu estoque de Bordeaux aos aldeões. O charlatão sai da cidade como o "grande Dulcamara, único entre os doutores".

Em Match Point, o papel da cultura deve ser comparado ao elixir de Dulcamara. De certa maneira, assim como Nemorino cai na armadilha do charlatão ao comprar vinho barato pensando se tratar de um poderoso elixir, o espectador de Match Point poderia aderir ao 
discurso da sorte enunciado pelo protagonista. No entanto, o som da gravação antiga e a recorrência de chiados sugerem certa impureza à sonoridade. Além dos ruídos, a utilização da ópera no filme suprime o início da famosa romanza, interpretada por Enrico Caruso. Aos fãs nostálgicos de Caruso, a introdução da ária é retirada. O trecho da ópera selecionado por Allen foi estendido e repetido, como se reafirmasse para o espectador o contraste entre ópera, discurso do protagonista e imagem apresentada.

Em Match Point, o uso da trilha sonora funciona como um comentário sobre a ação. Allen escolhe e intervém deliberadamente em fragmentos específicos das óperas utilizadas, de maneira que a trilha sonora funcione como um "colaborador ativo" (BRECHT, 1977, p. 85-86). Vejamos como essa função da trilha sonora se dá na introdução de Otello no filme. A música começa no escritório de negócios da família Hewett, localizado na torre do arquiteto-estrela Norman Foster, logotecture, em formato de ogiva nuclear, ou, como é conhecido popularmente, o "edifício pepino" incrustado no centro financeiro europeu. Sem precisar passar por um detector de metais no prédio high tech, mesmo após os atentados ao World Trade Center em $2001 \mathrm{em}$ Nova York, o executivo cheio de credenciais, trajado de terno e gravata, carrega a tiracolo uma arma de caça em sua mochila de tênis. Ao som da ópera de Verdi, observa-se o escritório de negócios através das janelas espessas da logotecture, entrecortadas por treliças metálicas. Da grande corporação, simbolizada pelo edifício em formato de projétil, Chris encaminha-se para o apartamento de Nola no subúrbio.

A equação do filme dá-se entre finanças, jogo e crime. No escritório da família Hewett, o executivo Rod Carver afirma que sente inveja do colega de trabalho, por conta de sua "energia extraordinária". Conforme o filme demonstra, trata-se de uma jornada comum, inserida na rotina do executivo de uma empresa transnacional. A introdução de Otello no coração financeiro europeu antecipa o crime e relaciona-o ao mundo dos negócios.

Enquanto instância separada da ação, a música extra-diegética comenta $o$ ato representado no filme, por exemplo, quando o tenor esbraveja que
Desdêmona é culpada: "Desdemona falsa!", a ópera aproxima o protagonista das exemplares personagens shakesperianas Otelo e Iago, os quais tornam-se indissociáveis. Nesse sentido, Chris representaria tanto o Mouro de Veneza, como a face mais perversa, Iago, "grande manipulador das histórias predominantes de sua sociedade" (SINFIELD, 1992, p. 29). De acordo com Helen Caldwell, as adaptações de Otelo costumam dispor as naturezas opostas dos dois personagens em um único homem:

[...] muitos estudiosos veem Iago como um símbolo do mal em Otelo e em todos os homens; outros vão mais além, a ponto de argumentar que Otelo é basicamente uma peça sobre o mistério, com Desdêmona representando Cristo, Iago, o demônio, e Otelo, o homem. Esta interpretação também se adéqua a Dom Casmurro, mas com uma nuança paradoxal, como é próprio de Machado de Assis. (CALDWELL, 2008, p. 155-156)

O uso de Otello em Match Point lembra a utilização da ópera em Dom Casmurro, de Machado de Assis. No romance brasileiro, Otello funciona como uma das pistas para desmascarar o discurso de Bentinho. No plano narrativo, a tragédia do Mouro de Veneza ajuda o narrador a se convencer da suposta traição de Capitu, em outro plano, Otello funciona como um indício para o leitor desmascará-lo. Ao assistir à ópera, Bentinho decide que não ele, mas Capitu deve morrer. O patriarca brasileiro chega a dizer que se Otelo foi capaz de estrangular a amada que era inocente por um simples lenço:

que faria o público se ela deveras fosse culpada? Tão culpada como Capitu? E que morte lhe daria o mouro? Um travesseiro não bastaria; era preciso sangue e fogo, um fogo intenso e vasto, que a consumisse de todo, e a reduzisse a pó, e o pó seria lançado ao vento, como eterna extinção... (ASSIS, 2004, p. 935).

Ao analisar as disputas interpretativas a respeito de Otelo, Sinfield lembra que todos os personagens estão contando histórias, no intuito de "convencer aos outros mais do que a eles próprios: há uma competição de histórias, e as condições de plausibilidade são, portanto, 
cruciais - elas determinam quais histórias serão críveis" (1992, p. 29-30). Ao analisar as condições de plausibilidade da tragédia shakespeariana, Sinfield explica que Otelo dispunha de duas alternativas centrais: "uma é aparentar ser muito calmo e responsável - assim como os venezianos imaginavam que eles mesmos fossem. Mas também, e inteligentemente, ele usa a ideia racista dele mesmo como um exótico" (1992, p. 30). Na análise da ópera de Verdi, Catherine Clément chega a conclusão semelhante. Para ela, Otello trata do conflito racista entre a cidade poderosa e o mouro: "todas as óperas de Verdi se prendem a um combate político ou ideológico. [...]. Otello não é somente um drama de ciúmes, é também sobre o conflito racista entre uma cidade poderosa e um mouro, do qual depende" (CLÉMENT, 2008, p. 30-31).

Sinfield entende que "racismo e sexismo na peça não devem ser característicos apenas de Iago, ou a sua maldade arbitrária, mas a cultura veneziana que estabelece as condições de plausibilidade" (1992, p. 31). O próprio Otelo considera-se inferior aos venezianos, na condição de estrangeiro: "Otelo 'reconhece' a si mesmo como aquilo que a cultura veneziana acreditava que ele fosse: um ignorante, forasteiro bárbaro" (SINFIELD, 1992, p. 31). O crítico lembra que Otelo utiliza o exotismo a seu favor, apresentando-se como mouro, e que a relação entre o personagem e Veneza baseia-se na dependência: "Até certo ponto, talvez, porque os senadores precisavam de Otelo para lutar contra os turcos, assim, eles permitem que a sua história prevaleça" (1992, p. 31).

A tragédia de Otelo trata da luta de um estrangeiro contra aqueles que representam, assim como ele, o Outro. Em nome de Veneza, o mouro combate os turcos; desse modo, a tragédia representa um combate fratricida. A batalha travada por Otelo por Veneza retoma momento anterior da utilização da trilha sonora no filme, a ópera Guillaume Tell, música diegética, encenada no Royal Opera House, sob o ponto de vista do camarote da família Hewett. Diferentemente de Tell, que lidera o levante dos suíços contra o jugo austríaco, Otelo defende aqueles que o oprimem. Match Point, não trata, portanto, da história do levante do oprimido contra o império, como na ópera de Rossini, mas da aliança entre Irlanda e Reino Unido e deste último com os EUA. Além disso, filmada em plena Guerra do Iraque, a tragédia contemporânea de Otelo em Match Point representaria o levante dos mouros em defesa de uma coalizão do Ocidente.

Em Match Point, as vozes de Otelo e Iago confundem-se, compondo uma espécie de monólogo interior de Chris Wilton. Enquanto o protagonista sobe as escadas do edifício de Nola na cena do assassinato, ouve-se na música extra-diegética a voz de Iago que trama contra Otelo, apresentando "a prova do pecado do amor". O uso da ópera no filme promove para o espectador uma espécie de aviso sobre o veneno de Iago/Chris: "o meu veneno trabalha". A introdução de fragmentos escolhidos da ópera comenta as ações do protagonista para o espectador. A colagem de fragmentos do segundo ato da ópera de Verdi refere-se ao momento em que Iago convence Otelo da traição de Desdêmona. Nesse momento, "Otelo é persuadido por Iago de sua inferioridade e da inconstância de Desdêmona e passa a agir como se isso fosse verdade" (SINFIELD, 1992, p. 31).

Ao avistar a saída dos vizinhos, Chris sobe as escadas, enquanto os espectadores do filme ouvem Otelo acusando Desdêmona: "Falsa contra mim! contra mim!" Por sua vez, Iago comenta a reação de Otelo: "Sofre e ruge!" Otelo repete: "Atroz! Atroz!" Otelo desesperase com a "ideia atroz". No filme, Chris vigia pelo vão da escada a entrada e saída dos moradores do prédio, enquanto dirige-se ao andar do apartamento de Nola. Nesse momento, na ópera, Iago aconselha Otelo: "Não pense mais nisso".

Quando Chris chega à porta da Sra. Eastby, a ópera apresenta o sofrimento do protagonista. Ouve-se Otelo e o barulho de Chris batendo à porta da Sra. Eastby. A música remete à suposta traição de Desdêmona. Por meio da introdução da música extra-diegética, o espectador observa a confusão inextricável dos sentimentos de Chris, suscitada pela ópera e pela imagem, uma espécie de "luta interior" (EISENSTEIN, 1932, p. 103).

No filme, o protagonista bate de maneira desesperada à porta da vizinha de Nola. Pode-se observar o reflexo da Sra. Eastby aproximando-se, enquanto a ópera comenta o desespero de Otelo: "meu peito se agita / talvez um presságio”. O anúncio da angústia de Otelo é 
seguido pela abertura de uma fresta da porta. Ela pede para que o estranho identifique-se. Nesse momento, a câmera aproxima-se do protagonista: "Eu sou o Chris, amigo da Nola, sua vizinha ao lado. Nós nos conhecemos.... A Sra. Eastby interrompe o estranho: "Desculpe-me, mas eu não deixo ninguém entrar".

Entreposto ao diálogo entre a Sra. Eastby e Chris, acompanha-se as lembranças de Otelo ao lado de Desdêmona. Ele canta referindo-se ao corpo, lábios e beijos da amada. Nesse ponto, o filme compara novamente Desdêmona e Nola. A utilização da música extra-diegética no momento em que Chris tenta convencer a vizinha aponta também para o objetivo primeiro do crime: $o$ assassinato da amada.

O executivo prossegue em direção à Sra. Eastby: "Você não se lembra? Nós nos conhecemos, a Nola perguntou alguma coisa sobre os problemas que estava tendo com ratos e você mencionou algo sobre manteiga de amendoim". A menção à pasta de amendoim, iguaria típica norte-americana, leva a vizinha a abrir a porta para o estranho: "Ah, sim, sim." Na ópera ouve-se a ira de Otelo, o qual sucumbe ao delírio: "Os beijos ardentes de Cassio! E agora! E agora!', fragmento que aponta para a derrota do Mouro de Veneza. No filme, a câmera muda de posição e o espectador observa Chris por intermédio do olhar da vítima, a Sra. Eastby.

Em Match Point, o lencinho de Desdêmona é substituído pela banalidade da manteiga de amendoim, isca fácil utilizada para convencer a vítima. Há na comparação lencinho/pasta de amendoim um comentário irônico de Woody Allen, tendo em vista que, conforme argumenta Sinfield, o lencinho, ou qualquer outra acusação, já seriam suficientes para Otelo, que está desde o começo convencido pela sociedade veneziana de que é "um marido inapropriado para Desdêmona ... As histórias de Iago funcionam porque são plausíveis - para Roderigo, Brabantio, o Senado, e até mesmo para o próprio Otelo" (1992, p. 30-31).

Enquanto entra no apartamento da vítima, o executivo apresenta-se: "Eu sou o Chris Wilton, professor de tênis". A Sra. Eastby pergunta o motivo da visita e em que poderia ajudá-lo; o assassino pede para checar o sinal de tevê. A ideia de que qualquer motivo serviria para o executivo entrar no apartamento está cifrada nesta cena que evidencia a desculpa improvisada do criminoso inexperiente e retoma o tema da indústria do entretenimento como cúmplice do crime, questão trabalhada por Dreiser. Na música extra-diegética, a ópera enuncia a derrota de Otelo, que dá adeus à memória: "Agora e para sempre, adeus santas memórias."

Enquanto a Sra. Eastby toma remédios, o protagonista monta a arma de caça da família Hewett. A ópera introduz a questão da memória, comentando sobre o esquecimento da vítima que não se lembra que Nola apresentara Chris como senhor Harris. Em diversos momentos, a ópera comenta as cenas e, neste ponto, Otelo canta dando adeus ao pensamento, à memória e à razão dos personagens: "Adeus, sublimes encantos do pensamento!". O canto de Otelo mostra a derrota do Mouro de Veneza, enunciando o declínio do personagem: "este é o fim da glória de Otelo".

A cena do momento em que Chris pega a arma do sogro às escondidas retoma conversa anterior no porão da casa de campo dos Hewett, o Englefield Estate (campo de batalha dos ingleses), no qual o patriarca instrui o futuro genro a utilizar a espingarda, pois Alec é um atirador de caça profissional. A prática do tiro é apresentada no filme - assim como ópera, literatura, artes plásticas, esportes e arquitetura - como distinção de classe. Alec oferece um curso de administração ao futuro genro, ao passo que monta a arma de caça da família, apontando-a para a câmera - a ameaça é também dirigida ao espectador. Após o acordo entre Chris e o patriarca, Tom oferece a espingarda para Chris. Alec, durante a cena do tiro no campo, avisa que transformará Chris em um "talentoso atirador".

Em imagem análoga no apartamento da Sra. Eastby, o executivo aponta a arma para a câmera, movimento que associa Chris ao patriarca. A cena do assassinato no edifício do subúrbio apresenta o protagonista como um atirador a serviço dos Hewett, em nome dos valores da grande corporação, empreendedorismo, família e propriedade, no campo, em Englefield, e na cidade, no Parliament View (edifício espelhado com vista para o Parlamento britânico). O filme retoma a ideia do "monopólio da violência legítima [...] a violência sobre a qual o Estado e a sua civilização repousam" (SINFIELD, 1992, p. 34-35). 
No apartamento do subúrbio, a vizinha recorda-se que o nome do companheiro de Nola era Harris. Na ópera, ouve-se Iago pedir a Otelo: "Paz, senhor". Otelo amaldiçoa-o pelas calúnias contra Desdêmona e pede "uma prova segura de que Desdêmona é impura". No filme, Chris caminha com a arma apontada em direção à câmera. Ele dirige-se ao cômodo onde a Sra. Eastby toma os remédios. O espectro sombrio do protagonista, ressaltado pela vestimenta e pela iluminação do local, relembra o Mouro de Veneza.

$\mathrm{Na}$ ópera, Otelo contesta Iago e pede uma prova visível: "Não fuja! Nada te ajudará! Quero uma prova visivel, segura!". Fechando o frasco de remédios, a Sra. Eastby olha para a câmera em direção ao assassino. Em rápido contraplano, observa-se Chris atirar contra a vizinha. A arma de fogo e o barulho do tiro invadem a ópera. Após o disparo, não ouvimos mais a voz dos personagens no filme, apenas a música extra-diegética, a voz de Otelo e Iago narram os acontecimentos.

Ao disparar contra a Sra. Eastby, Chris treme e cai no chão. O protagonista é tomado pelo desespero e choro. Chris revira os pertences da vizinha, simulando um assalto. Na cena do assassinato da Sra. Eastby, observase um saqueio: Chris rouba os remédios, o relógio e os anéis da vítima. $\mathrm{O}$ anel de casamento retoma a ideia da aliança entre Chris e os Hewett. O saqueio não é contra os ricos, mas sim contra a vizinha a Sra. Eastby, cujo nome retoma a questão dos pobres do Leste europeu, no apartamento do subúrbio londrino.

Reafirmando a evidência de que não se trata de um roubo, o protagonista chuta a bolsa da Sra. Eastby e chora, sentado no sofá da vítima à espera de Nola. O filme volta a destacar o aspecto rotineiro do assassinato, como se o crime fosse a regra, o eterno reinstaurar da ordem estabelecida. Assim como a heroína shakesperiana, a norte-americana é "uma mulher que poderia provocar uma crise na história patriarcal ... Ela coloca o sistema em desordem" (SINFIELD, 1992, p. 45) e por isso, é eliminada pela própria ordem patriarcal, por meio de seus agentes. Vale lembrar que Nola fora eliminada, primeiramente, dentro da família Hewett; portanto, Chris cumpre a sentença proferida anteriormente pela matriarca Eleanor. O mouro de Veneza é caracterizado como um servo do Estado veneziano, en- viado para matar os turcos e Desdêmona, que desafia o pai ao casar-se com o mouro. Otelo acaba apunhalando a si mesmo, restabelecendo a ordem em nome da sociedade veneziana.

Woody Allen contrapõe, por meio de dois cortes rápidos, o sofrimento do protagonista no apartamento da Sra. Eastby à calmaria da rua onde Nola pega um táxi. Enquanto o assassino "sofre e ruge!", a vítima dirige-se à residência após o trabalho, como uma passante desconhecida. Nola, seu filho e a Sra. Eastby compartilham um destino comum, marcado pela violência. Enquanto Chris guarda os pertences da Sra. Eastby na mochila de tênis, ele olha para o relógio, reafirmando a ideia do crime premeditado que assim como o trabalho é controlado pelo tempo.

O cineasta corta para a fachada do Palace Theatre, onde está em cartaz o musical The Woman in White, onde Chloe espera pelo marido. A ida ao teatro faz parte da rotina do casal, e o crime deve ser executado anteriormente ao evento programado com a esposa. $\mathrm{Na}$ rua do apartamento de Nola, observa-se a sua chegada, simultânea à entrada de Chloe na sala de concerto. Nesse momento, ouve-se a música extra-diegética, na qual Iago falseia o sonho de Cássio a Otelo: "Desdêmona doce! O nosso amor se esconde". Apesar de se tratar da narrativa de Iago, a utilização deste trecho da ópera retoma o amor de Chris por Nola. Enquanto isso, o protagonista coloca as balas na espingarda. Observa-se um vizinho descendo as escadas do edifício, o que mostra que mesmo após o assassinato da Sra. Eastby, a rotina dos moradores permanece inalterada.

Outro indício do cotidiano dos moradores ocorre no momento em que o vizinho Ian (Colin Salmon) tenta chamar a Sra. Eastby: "Eu vou à loja da esquina, quer que eu traga algo?". Chris esconde-se atrás da porta e escuta o chamado de Ian, personagem interpretado por um ator negro. Na inversão dos papeis de Otelo em Match Point, Otelo e Iago são brancos; Ian seria Cássio. No trecho da ópera apresentado nesta parte do filme, Iago prossegue contando a Otelo o sonho de Cássio. Ian e Chris estão apenas separados pela porta do apartamento da Sra. Eastby. Chris cometerá os assassinatos, sem que os vizinhos percebam. Ao sair do edifício, Ian encontra Nola. Os dois conversam sobre um tocador de 
$\mathrm{CD}-\mathrm{R}$ portátil, conversa trivial que remete à indústria do entretenimento.

Da escadaria do prédio em contra-plongée, a câmera focaliza o protagonista. A imagem de Chris aparece por meio das estruturas metálicas que compõem o corrimão da escada do edifício no subúrbio e retoma a apresentação do edifícios de negócios na City. Em Match Point, filme que retrata o percurso de um arrivista social, as escadarias representam a trajetória ascendente do protagonista, notadamente, no Englefield Estate, na casa de Alec e Eleanor em Londres e no apartamento de Chloe e Chris no Parliament View. Enquanto Chris vigia a chegada de Nola por meio do vão da escadaria, a voz de Otelo reafirma o sofrimento do protagonista: “Oh, monstruosa culpa!". Na entrada do edifício, Nola despede-se de Ian. Na ópera, Iago explica a Otelo que se trata apenas de um sonho: " $E u$ não narrei mais do que um sonho". Otelo precipita-se a Iago, ao afirmar que se trata de: "Um sonho que revela um fato". Iago, por sua vez, argumenta que o sonho pode comprovar outro indício.

Nesse momento, Nola entra no prédio. Do lado de dentro do edifício, Chris observa Nola com a arma em punho. A iluminação escura da cena permite que se observe o protagonista como uma sombra negra. Nesse ponto, a música extra-diegética é cortada. Allen opta por não apresentar o momento da ópera no qual Iago traz o "indício" para Otelo, o lencinho de Desdêmona. Ao cortar este fragmento específico da ópera, o filme comenta Otello, mostrando, conforme já argumentamos, que o mouro de Veneza não precisa do sonho de Cássio nem do lencinho de Desdêmona, pois desde o começo da ópera, Otelo já se considerava à semelhança da imagem que lhe foi atribuída pela sociedade veneziana. Movimento análogo ocorre em Match Point: Chris reafirma a ordem patriarcal ao cometer os assassinatos de Nola, de seu filho e da Sra. Eastby. O filme apresenta todos os passos do crime: da trajetória de aliança do irlandês com as classes dominantes britânicas, à possibilidade - ao lado de Nola - de saída do claustro e, por fim, a execução da companheira.

Allen retira o momento do lencinho e passa a repetir pequenos fragmentos da ópera. Ouve-se a voz do tenor e do barítono e é possível identificar algumas pa- lavras, tais como, "culpa", "amor" e "suspiros". Reitera-se o tema da morte do sujeito. Os "suspiros" retomam a ópera de abertura $O$ Elixir de Amor, na qual Nemorino suplica pelos murmúrios da amada.

No plano da imagem, Chris fica à espreita de Nola. Observa-se o protagonista segurar a espingarda e atirar contra Nola, em direção à câmera; portanto, sugere-se também a ameaça contra o espectador. Há um rápido corte que mostra Chloe, no aguardo, em frente ao Palace Theatre para assistir ao musical.

Saindo do edifício de suas vítimas, o assassino esbarra em um transeunte. Na ópera, Otelo grita: "Sangue, sangue, sangue". Mas, a rotina restabelece-se. Dentro do táxi, o protagonista comunica a Chloe que está a caminho. Durante o percurso até o teatro, Chris chora e desespera-se. Na música extra-diegética pode-se ouvir o dueto de Otelo e Iago: "Pela morte e pelo mar obscuro destruidor!", comentário à conversa entre marido e esposa.

A cena seguinte mostra Chloe e Chris descendo as escadarias de mármore do teatro. Nesse ponto, a ópera é bruscamente interrompida. O protagonista deixa seus pertences na chapelaria do local (o casaco e a mochila de tênis, onde guarda a arma do crime e as joias e remédios da Sra. Eastby). Na cena, evidencia-se que o executivo e sua esposa são insuspeitos, frequentadores comuns do teatro. Na plateia, entre os outros espectadores, a câmera apresenta o olhar hipnotizado da herdeira, que prefere o musical à ópera, e os olhos marejados do protagonista - semelhante à "furtiva lágrima" de Nemorino. Enquanto assistem hipnotizados à apresentação, ouve-se o início da música diegética. A melodia é invadida e interrompida pelas sirenes da polícia. Para o espectador, a referência a The Woman in White relembra Nola. No desfecho do filme, a ida ao espetáculo cultural retoma a questão da indústria do entretenimento como cúmplice do crime.

A preferência de Chloe Hewett pelo espetáculo de balé e o musical, em detrimento da ópera, ilustra a questão da cultura como entretenimento. De acordo com Brecht, "a ópera é vendida como entretenimento noturno e isso coloca limites definitivos para todas as tentativas de transformá-la" (BRECHT, 1977, p. 41). No entanto, a utilização das óperas em Match Point permi- 
te a análise a contrapelo, desvendando a barbárie que a cultura procura esconder, o extermínio de inocentes.

A Scotland Yard desconfia do homem negro e desconsidera o depoimento da principal testemunha do crime, além disso atribui o crime a um dependente de drogas que já possuía condenações anteriores. No filme, a função da polícia é proteger o executivo. Diferentemente de Raskólnikov, Chester Gillette, Clyde Griffiths e George Eastman, Chris conta com uma "rede de proteção" que o salvaguarda, ocultando crimes e erros financeiros. Anteriormente à crise financeira de 2008, a família Hewett configura-se entre as corporações que são "grandes demais para falir". Como avesso do destino do protagonista de Dreiser - Clyde Griffiths que é inocente, mas condenado à cadeira elétrica -, o protagonista do filme de Woody Allen representa o crime sem castigo, no qual o assassino é promovido na empresa transnacional. Em Match Point, uma tragédia americana do início do século XXI, o status quo protege criminosos e propaga o assassinato de inocentes no show de entretenimento.

\section{Notas}

1. Este artigo faz parte de trabalho mais amplo, realizado desde a dissertação de mestrado. Ver referências bibliográficas.

2. Um ano após o lançamento de Match Point, celebrou-se nos EUA o centenário do assassinato de Grace Brown, que inspirou o romance Uma Tragédia Americana. A pacata região de Adironback, no norte do estado de Nova York, planejava receber hordas de turistas e peregrinos para conhecer o local do crime (YORK, 2006).

3. Esta e as demais traduções são de minha autoria, exceto quando indicado nas referências bibliográficas.

4. Na recente convenção do Partido Republicano, o famoso slogan fascista de Mussolini aos cidadãos norte-americanos foi reeditado pelo candidato Donald Trump, que conclamou os eleitores a "fazer a América grande de novo" (BUMP, 2016).

5. A partir da pesquisa na coleção "Papéis de Woody Allen", analiso as modificações que foram feitas por Woody Allen e sua equipe no roteiro de Match Point na passagem de Nova York para Londres. Ver tese de Doutorado em Referências bibliográficas.

6. Existem duas traduções para o português do artigo de Eisenstein; ambas utilizam a versão norte-americana do texto, originalmente publicado em russo na Proletarskoye Kino, nº17/18, em 1932. Na tradução em inglês, o texto está publicado com o título "A Course in Treatment", no livro Film Form, editado e traduzido por Jay Leyda. A versão utilizada neste trabalho parte do livro A Forma do Filme, traduzido por Teresa Otoni. A primeira versão para o português foi feita por Vinicius Dantas e pode ser encontrada sob o título " $\mathrm{Da}$ Literatura ao Cinema: Uma Tragédia Americana", na antologia A Experiência do Cinema, organizada por Ismail Xavier.

7. As filmagens feitas por George Stevens, John Ford, entre outros cineastas de Hollywood que formavam a Unidade de Cobertura Especial do Exército Americano, foram usadas posteriormente como evidências dos crimes nazistas no Tribunal Militar Internacional em Nuremberg. Ver: "John Ford, Samuel Fuller and George Stevens. Filming the camp: from Hollywood to Nuremberg". In: Memorial de la Shoah. 31 de agosto de 2010. Disponível em: <http://www. memorialdelashoah.org/upload/minisites/filmer_les_ camps/en_index.html >. Acesso em 23 jul.2016.

8. Ver: "World War Two as you have never seen it: extremely rare colour footage of D-Day invasion released". In: The Telegraph. 29 de maio de 2014. Disponível em: <http://www.telegraph.co.uk/history/ world-war-two/10861960/World-War-Two-as-youhave-never-seen-it-extremely-rare-colour-footageof-D-Day-invasion-released.html>. Acesso em 23 jul.2016.

9. Dalton Trumbo foi um dos Hollywood Ten, grupo de escritores e diretores de Hollywood que em 1947 foram presos por se recusarem a delatar outros colegas ao Comitê de Atividades Antiamericanas (HUAC).

10. Transcrição e tradução minha de breve trecho apresentado no primeiro capítulo de Histoire $(s) d u$ cinema (1989), de Jean-Luc Godard.

11. Resumo meu a partir de: Donizetti, Gaetano. O Elixir de Amor; trad. Manuel Rosa. Lisboa: Série Óperas Imortais, Editorial Notícias, 1984, p. 24-25, e Kobbé, Gustave. O Livro Completo da Ópera. Rio de Janeiro: Jorge Zahar Ed., 1997, p. 261-263.

\section{Referências}

ANJOS, Ana Paula Bianconcini. Capital Financeiro e Empreendedorismo: Considerações sobre o Sujeito Contemporâneo em Match Point, de Woody Allen. 2010. Dissertação (Mestrado em Estudos Linguísticos e Literários em Inglês) - Faculdade de Filosofia, Letras e Ciências Humanas, Universidade de São Paulo, São Paulo, 2010. Disponível em: <http://www.teses.usp. br/teses/disponiveis/8/8147/tde-20092010-143226/>. Acesso em: 25 jul.2016. 
A Cidade Cartão-Postal no Cinema de Woody Allen. 2015. Tese (Doutorado em Estudos Linguísticos e Literários em Inglês) - Faculdade de Filosofia, Letras e Ciências Humanas, Universidade de São Paulo, São Paulo, 2016. Disponível em <http://www.teses.usp.br/ teses/disponiveis/8/8147/tde-29062016-124522/pt-br. php>. Acesso em 23 jul.2016.

ASSIS, Machado de. "Dom Casmurro". In: Obras Completas - vol.1. Rio de Janeiro: Nova Fronteira, 2004.

BRECHT, Bertolt (1898-1956). "Texts and Fragments on the Cinema (1919-1955)". In: Brecht on Film and Radio; transl. and edited by Marc Silberman. Rayleigh, Essex: Methuen, 2000.

Brecht on Theatre: The Development of an Aesthetic; trad. e ed. John Willett. Nova Iorque: Hill and Wang, 1977.

BUMP, Philip. "In 1927, Fox News Service Filmed Benito Mussolini telling immigrants to 'make America great"”. In: The Washington Post. 23 jul.2016. Disponível em: <https:/www.washingtonpost.com/ news/the-fix/wp/2016/07/23/in-1927-fox-newsservice-filmed-benito-mussolini-telling-immigrantsto-make-america-great $/$ ? wpisrc $=$ nl_wemost draw5\&wpmm=1>. Acesso em 23 jul.2016.

CALDWELL, Helen. Otelo Brasileiro de Machado de Assis: um estudo de Dom Casmurro; trad. Fábio Fonseca de Melo. São Paulo: Ateliê Editorial, 2008.

CLÉMENT, Catherine. A Ópera ou a Derrota das Mulheres; trad. Rachel Gutiérrez. Rio de Janeiro: Rocco, 1993.

DONIZETTI, Gaetano. O Elixir do Amor; trad. Manuel Rosa. Lisboa: Série Óperas Imortais, Editorial Notícias, 1984, p. 24-25.

DREISER, Theodore. An American Tragedy (1925). New York: Signet Classic, 2000.

EISENSTEIN, Sergei. “Sirva-se!". In: A Forma do Filme. Apresentação, notas e revisão técnica de José Carlos Avelar; trad. Teresa Otoni. Rio de Janeiro: Jorge Zahar Ed., 2002. p. 89-107.

"Da Literatura ao Cinema: Uma Tragédia Americana"; trad. Vinicius Dantas. In: XAVIER, Ismail (org.). A Experiência do Cinema: antologia. Rio de Janeiro: Edições Graal: Embrafilmes, 1983, p. 203-215.

"A Course in Treatment". In: Film Form: Essays in Film Theory; ed. trad. Jay Leyda. New York: Harcour Brace \& Company, 1977, p. 84-107.

GEORGE STEVENS E A SEGUNDA GUERRA MUNDIAL. "World War Two as you have never seen it: extremely rare colour footage of D-Day invasion released". In: The Telegraph. 29 de maio de 2014. Disponível em: <http://www.telegraph.co.uk/history/ world-war-two/10861960/World-War-Two-as-youhave-never-seen-it-extremely-rare-colour-footageof-D-Day-invasion-released.html>. Acesso em 23 jul.2016.

HUSSMAN, Lawrence. "Squandered Possibilities: the Film Versions of Dreiser's Novels". In: GOGOL, Miriam. Theodore Dreiser: Beyond Naturalism. New York: New York University Press, 1995. p. 176-200.

KOBBÉ, Gustave. O Livro Completo da Ópera; trad. Clóvis Marques. Rio de Janeiro: Jorge Zahar Ed., 1997.

MATLOFF, Jason. "Woody Allen's European Vacation", In: JasonMatloff.com, 2010. Disponível em: <http:// jasonmatloff.com/selected-articles/woody-allenseuropean-vacation/>. Acesso em 23 jul.2016.

MERCK, Mandy. Hollywood's American Tragedies: Dreiser, Eisenstein, Sternberg, Stevens. Oxford; New York: Berg, 2007.

SARLO, Beatriz et al. Jean-Luc Godard, el pensamiento del cine: cuatro miradas sobre Histoire(s) du cinéma. Buenos Aires: Paidós, 2003.

SINFIELD, Alan. "Cultural materialism, Othello, and the politics of plausibility". In: Faultlines: cultural materialism and the politics of dissent teading. Berkeley: University of California Press, 1992. p. 2951.

TRUMBO, Dalton. "It Will Be Broken - Dalton Trumbo, Letter to the producer George Seaton, 20 January 1959". In: SILVESTER, Christopher (ed.). The Grove Book of Hollywood. New York: Grove Press, 1998, p. 461-465.

ULMER, James. “A Guild Divided”. In: Directors Guild of America. Los Angeles, 2011. Disponível em: <http:// www.dga.org/Blacklist>. Acesso em 23 jul.2016.

WILLIAMS, Raymond. Tragédia moderna; trad. Betina Bischof. São Paulo: Cosac \& Naify, 2002.

WRIGHT, Alan. "Elizabeth Taylor at Auschwitz: JLG and the Real Object of Montage". In: TEMPLE, Michael; Williams, James (ed.). The cinema alone: essays on the work of Jean-Luc Godard, 1985-2000. Amsterdam: Amsterdam University Press, 2000. p. 51-60.

XAVIER, Ismail. "O olhar e a voz: a narração multifocal do cinema e a cifra da História em São Bernardo". In: Literatura e Sociedade, São Paulo, v. 2, p. 126-138, 1997.

YORK, Michelle. "Century After Murder, American Tragedy Draws Crowd". In: The New York Times. 11 jul.2006. Disponível em: <http://www.nytimes. com/2006/07/11/nyregion/11tragedy.html?_r=0>. Acesso em 23 jul.2016. 


\section{Filmes:}

AURORA. Direção: F. W. Murnau. Roteiro: Hermann Sudermann (conto); Carl Mayer; Katherine Hilliker; H.H. Caldwell. Produção: William Fox. Intérpretes: George O’Brien; Janet Gaynor; Margaret e outros. Los Angeles: Fox Film Corporation, 1927. 1 DVD (94 min), p\&b.

HISTOIRE(S) du Cinéma (capítulo 1). Direção e Roteiro: Jean-Luc Godard. Paris: Canal+; La Sept; France 3 (FR 3), 1989. 1 DVD (51 min), color.

LUGAR ao Sol, Um. Direção e Produção: George Stevens. Roteiro: Theodore Dreiser (romance), Patrick Kearney, Michael Wilson, Harry Brown. Intérpretes: Montgomery Clift, Elizabeth Taylor, Shelley Winters e outros. Los Angeles: Paramount Pictures, 1951. 1 DVD (122 min), p\&b.

MATCH POINT, Ponto Final. Direção e Roteiro: Woody Allen. Produção: Letty Aronson; Charles H. Joffe; Jack Rollins; Helen Robin; Stephen Tenenbaum; Lucy Darwin; Nicky Kentish Barnes; Gareth Wiley. Intérpretes: Jonathan Rhys Meyers, Scarlett Johansson, Emily Mortimer, Matthew Goode e outros. Londres: BBC Films, 2005. 1 DVD (119 $\mathrm{min})$, color.

TRAGEDY American, An. Direção e Produção: Josef von Sternberg. Roteiro: Theodore Dreiser (romance). Intérpretes: Philip Holmes; Sylvia Sidney; Frances Dee e outros. Los Angeles: Paramount Pictures, 1931. 1 DVD (96 min), p\&b.

Recebido em: 01/03/2016 Aceito em: 08/08/2016 